\title{
ENTRE A UNIVERSALIDADE E A CRITICIDADE: A QUESTÃO DA PRÉ-COMPREENSÃO DESDE GADAMER E HABERMAS
}

\author{
Ivone Fernandes Morcilo Lixa ${ }^{1}$ \\ Leonardo da Rocha de Souza ${ }^{2}$
}

Resumo: O presente trabalho pretende discutir brevemente um dos grandes desafios no campo da hermenêutica jurídica, a questão da pré-compreensão, desde os dois grandes herdeiros do pensamento moderno: Hans-Georg Gadamer e Jürgen Habermas. Trata-se de trazer para o campo jurídico uma problemática central e contemporânea da hermenêutica, qual seja, a pré compreensão ou convicção prévia, enquanto componente hermenêutico tradicionalmente negado pelas práticas instrumentais tecnicistas. Tal discussão ganha relevância no direito contemporâneo brasileiro quando práticas judiciais são impregnadas por decisionismos e pragmatismos em nome de uma justiça possível.

Palavras chave: Hermenêutica Jurídica - Pré-Compreensão - Crítica à tradição - Crítica à ideologia - Cultura política

\section{BETWEEN THE UNIVERSALITY AND THE CRITICALITY: THE CASE OF PRE-COMPREHENSION SINCE GADAMER AND HABERMAS}

\begin{abstract}
This work intends to briefly discuss one of the great challenges in the field of legal hermeneutics, the case of pre-comprehension by two great heirs of modern thought: Hans-
\end{abstract}

\footnotetext{
${ }^{1}$ Pós doutora em Direito pela Universidade Federal de Santa Catarina (UFSC - 2014). Doutora em Direito Público - Universidad Pablo de Olavide - Universidade Federal de Santa Catarina (UFSC) (2008). Mestre em Filosofia do Direito pela Universidade Federal de Santa Catarina (2000). Graduada em Direito pela Fundação Universidade Regional de Blumenau (1998), Pós Graduação em Direito Civil pela Universidade Regional de Blumenau (1998). Possui graduação em Ciências Geograficas pela Universidade de São Paulo - USP - (1980), graduação em Geografia pela Universidade de São Paulo - USP - (1980). Atualmente é professora visitante da Universidad de San Luis de Potosi (San Luis de Potosi - México - Maestria en Derechos Humanos). Professora da Escola Superior da Magistratura de Santa Catarina, professora contratada do Centro Universitário Católica de Santa Catarina (Graduação e Pós Graduação em Direito) e professora titular das disciplinas de Hermenêutica Jurídica e História das Instituições Jurídicas da Universidade Regional de Blumenau no Curso de Direito.

2 Pós-doutor em Direito (UFRGS). Doutor e Mestre em Direito (UFRGS). Bacharel em Direito (UNISINOS). Licenciado em Ciências Sociais (ULBRA). Especialista em Ética e Filosofia Política (UCS). Diplomado pela Escola Superior da Magistratura (AJURIS). Professor Efetivo da Universidade Regional de Blumenau (FURB) (2017-atual). Vice-líder do grupo de pesquisa CNPq/FURB 'Direitos Fundamentais, Cidadania e Justiça'. Procurador do Município de Caxias do Sul-RS (2009-2017). Professor Adjunto da Universidade de Caxias do Sul, com atuação na graduação em Direito e no Programa de Pós-graduação Stricto Sensu em Direito como membro do corpo permanente (2014-2017). Pesquisador do Grupo de Pesquisa CNPq/UFRGS 'Sociologia Judiciária Clínica de Estudos Interdisciplinares sobre o Direito, a Justiça e o Poder Judiciário'. Vice-líder do Grupo de Pesquisa CNPq/UFRGS 'Direitos Fundamentais e Novos Direitos' liderado pelo Prof. Dr. José Alcebíades de Oliveira Junior. Editor Científico da Revista Juris Plenum Direito Administrativo (Qualis B1 - avaliação 2016).
} 
Georg Gadamer and Jürgen Habermas. It is discuss the case in the legal field trough a central and contemporary hermeneutical problematic, that is, the pre-understanding or previous conviction, as a hermeneutic component traditionally denied by instrumental technicalist practices. Such discussion receives relevance in contemporary Brazilian law when judicial practices are impregnated by decisionisms and pragmatism in the name of possible justice.

Keywords: Hermeneutic Legal - Pre-comprehension - Criticize to tradition - Criticize to ideology - Political culture

\section{Introdução: colocação do problema.}

No Brasil em tempos de decisionismos (STRECK, 2014, p. 38-47) e quando o moralismo suplanta a legalidade, são visibilizados, mais do que nunca, os inegáveis limites e impossibilidades da "razão jurídica libertadora” legada pelos iluministas. Sem dúvida, o Direito moderno e seus paradigmas de sustentação, dentre os quais o da legalidade, foi um audacioso projeto e idealizado, que, desde seu início, trazia em si, um conjunto de representações e perspectivas que pareciam anunciar o triunfo da lei dos homens sobre o arbítrio. Esta racionalidade aplicada à organização social e política prometia a certeza de uma sociedade estável, democrática e justa. Assim, a justificativa de necessidade de submissão social e política à razão jurídica significava a segurança definitiva contra qualquer imprevisibilidade do "mundo da natureza”, certeza que se tornou tragédia anunciada no século XX, com as guerras mundiais e regimes totalitários, bem como nas primeiras décadas do XXI com as tragédias humanitárias, desmanche dos Estados Democráticos e retrocessos constitucionais.

O modelo de racionalidade jurídica moderna trouxe também em si, em uma de suas faces, a necessidade de não apenas justificar técnica e politicamente a criação do direito pelo Estado, mas sua interpretação e aplicação, desde o positivismo jurídico em suas distintas versões, definindo a Hermenêutica no campo jurídico como saber técnico metodológico acerca da norma positivada. Na esteira desse pensamento floresceu e predominou a convicção de que o sistema normativo possui em si intrinsecamente todos critérios necessários para resolver os conflitos jurídicos, não necessitando o jurista recorrer a nenhuma outra fonte para além daquelas estabelecidas pelo legislador. Nesta perspectiva, tendencialmente a ordem jurídica possuiria capacidade de autointegração, devendo, portanto, seus operadores estarem submetidos exclusivamente à lei, sendo então, a administração da justiça a administração do Direito legal.

A Hermenêutica Jurídica definiu-se, portanto, inicialmente, como possibilidade da certeza do sentido da norma e desde então, desde o positivismo exegético até o normativismo 
kelseniano, criaram-se teses e fundamentos hermenêuticos que entre discussões e aporias (tipo: voluntas legis versus voluntas legislatoris ou objetivismos versus subjetivismos) que acabaram por situar a questão hermenêutica no campo metodológico, que mais servem como justificativa (álibis teóricos) de legitimação para os resultados que o intérprete se propõe a alcançar ou/e garantir.

É esta tradição hermenêutica que acabou confinando a tarefa hermenêutica no campo epistemológico, especialmente metodológico formal, adquirindo status de instância racional do texto legal de forma a possibilitar a superação das aparentes contradições da ordem dogmática, “adequando” o significado da norma ao contexto de sua aplicação. As teorias hermenêuticas de matriz formal legalista, não dando conta, ou considerando alheio a sua tarefa, elaborar um saber jurídico-normativo adequado a uma justa compreensão do problema concreto, dirigem todo esforço no sentido de elaborar “corretos” critérios, cânones ou procedimentos capazes de produzir uma “boa” interpretação no sentido mais exegético possível.

Em síntese, definida como saber específico acerca da compreensão do sentido, “Hermenêutica Jurídica” é uma expressão que historicamente foi carregada de imprecisões. Na tradição clássica exegética, o grande esforço teórico em sua origem foi o de delimitar regras para eliminar as arbitrariedades e subjetivismos interpretativos e, com essa preocupação, é que se definiram as concepções univocistas, paradigmas dominantes no século XIX e início do XX. Com as contribuições de Heidegger e Gadamer é reorientado seu objeto, assumindo-se a Hermenêutica como filosofia universal da interpretação, considerando a interpretação a característica essencial da presença humana no mundo. Um avanço que acabou por definir o panorama do pensamento hermenêutico contemporâneo, discussão que permanece em aberto no campo jurídico, uma vez que se tornou inegável o papel da pré-compreensão no processo hermenêutico.

Em contraponto às correntes tradicionais que defendem a neutralidade, e por via de consequência no campo hermenêutico que nega a pré-compreensão (tradicionalmente chamada de subjetividade) emerge no Direito o chamado pensamento jurídico crítico. Composto por distintas e inúmeras “vozes” e tendências que colocam em debate a questão da fundamentação da “verdade” destacadamente através de duas grandes concepções teóricas: a questão dialética da verdade (representada pelo pensamento habermasiano), e a questão da hermenêutica como verdade para além do método (de matriz gadameriana). 
As duas posições polarizadas giram em torno da questão filosófica maior: a questão da reflexão. A reflexão, para Ernildo Stein (1987, p. 102), pretende através da oposição produzir uma identidade, distanciamento entre a consciência de si e do outro. A consciência, portanto, se constrói quando relacionada com outro conteúdo estranho e definida pela reflexão, oposição e unidade. Na base da estrutura da reflexão é que podem ser consideradas a crítica e a hermenêutica com suas propostas metodológicas, ambas defendendo a possibilidade de universalidade e verdade. A "diferença" e a "mediação" como procedimentos distintos da reflexão reivindicam incompatível status teórico com dois métodos e duas concepções filosóficas. Posições defendidas em campos opostos por dois grandes, e seguramente últimos, representantes da modernidade: Habermas e Gadamer. ${ }^{3}$

O presente trabalho pretende brevemente discutir elementos nucleares da contraposição entre ambos pensadores, destacadamente quanto à problemática da précompreensão, com vistas a trazer ao campo jurídico elementos para uma hermenêutica jurídica para além do infinito relativismo e nocivo decisionismo, ou seja, desde a criticidade de tradição e do marxismo.

\section{Entre a tradição marxista e a hermenêutica.}

Para melhor visualizar o confronto entre marxistas e a tradição hermenêutica devese considerar a trajetória e paralelismo dos dois pensadores. Gadamer nos anos 1960 publica Verdade e Método explicitando a tese de uma hermenêutica filosófica a partir da tradição e de forte crítica à herança iluminista. Habermas em 1967 publica seu estudo A Lógica das Ciências Sociais no qual apresenta o método crítico dialético contrapondo-se e apontando as insuficiências da racionalidade hermenêutica. Na mesma época Gadamer publica um ensaio $A$ universalidade do problema hermenêutico seguido de uma resposta à Habermas: Retórica, Hermenêutica e Crítica à Ideologia. Em 70 Habermas realiza um balanço crítico entre a dialética e a hermenêutica publicando A pretensão de universalidade da hermenêutica. $\mathrm{O}$

\footnotetext{
3 Há que se lembrar que ambos pensadores representam a tradição crítica à modernidade vindos de distintas matrizes. Gadamer estudou em Malburgo tendo doutorado-se em 1922 sob a orientação de Paul Natorp. Habilitouse para o magistério superior orientado por Martin Heidegger que acabava de produzir Ser e Tempo, tornando-se seu principal seguidor. Habermas vem de fontes diferentes. Foi discípulo e amigo de Theodor Adorno e de seus estudos sobre Marx e Freud é que surge a preocupação com a emancipação. Participa ativamente dos movimentos estudantis da década de 60 perseguindo sempre a reflexão sobre as condições do diálogo livre da dominação. Gadamer interessa-se pelas condições de possibilidade da compreensão e interpretação. Habermas, indo além dos frankfurtianos, estuda as condições de possibilidade da comunicação humana livre de patologias sociais e individuais.
} 
debate ganhou espaço acadêmico e muitos entram na discussão, a exemplo de K. O. Apel com sua A transformação da filosofia e Paul Ricoeur, cujas contribuições servirão de contraponto e mediação para a discussão.

Um ponto inicial para compreender o debate e a aproximação de Habermas com a hermenêutica é a consideração de que o marco institucional de uma sociedade se compõe de normas que dirigem interações linguisticamente mediadas (HABERMAS, 1986, p.71). Distinguindo entre o marco institucional, ou mundo sociocultural da vida, e os subsistemas de ação racional em relação aos fins, entende que, no que chama de capitalismo tardio, há uma crescente expansão das forças produtivas através da permanente expansão dos subsistemas traduzidos na linguagem que vão se ajustando por uma racionalidade comunicativa de jogos linguísticos confrontados no umbral do mundo moderno com uma racionalidade fim-meio que se liga a uma ação instrumental. Neste contexto é que Habermas explica o interesse pela hermenêutica. As disciplinas hermenêuticas históricas são aquelas reguladas por um interesse prático, para as quais o acesso aos fatos se realizam mediante a compreensão do significado.

O ponto crucial de discordância com Gadamer diz respeito à relação entre o poder da reflexão e o conhecimento, o que torna autorreflexão um fenômeno complexo. É exatamente aí que está a tarefa da Teoria Crítica, a de buscar as falsas relações, o que para Habermas foi negligenciado por Gadamer. O fato de concordar com Gadamer acerca da crítica ao objetivismo não teria eliminado o equívoco de solucionar o problema tão somente pela crítica ao objetivismo, o que para Habermas, é até uma certa ingenuidade. A redução à linguagem do complexo da convivência seria a entrada em um círculo do qual não se escapa de sérias consequências morais e éticas. A crença de que a apropriação reflexiva como único elemento de crítica à tradição não significa que se rompa ou que a modifique substancialmente.

Para Habermas o erro de Gadamer foi o de eleger o caminho de contraposição da “verdade” ao "método” por conduzir também a oposição entre a "experiência hermenêutica” ao "conhecimento metódico", o que é fundamento das ciências sociais. O projeto hermenêutico habermasiano retoma o estudo das ciências que estudam a realidade simbolicamente estruturada do mundo e buscam explicar, nesta perspectiva, a estrutura mais profunda da ordem social, chegando à Teoria da Ação Comunicativa, que resgata do projeto kantiano o fato de que a razão reflete sobre condições universais, afirmando:

...entendo por ação comunicativa uma interação simbolicamente mediada. Se orienta com normas intersubjetivamente vigentes que definem a expectativa recíproca de comportamento e que devem ser compreendidas e reconhecidas, por ao menos, dois 
sujeitos agentes. As normas sociais são marcadas por sanções. Seu sentido se objetiva na comunicação lingüística cotidiana (HABERMAS, 1986, p. 68-69).

Ao analisar o que é inerente à atividade de comunicação, entende Habermas que a hermenêutica contribuiu para introdução de um elemento importante para análise da linguagem: a historicidade. Mas é insistente ao chamar atenção para o fato de que aquilo que é pré-existente e fundado pode estar presente na comunicação como uma forma de dominação sob o "manto" de uma pseudo-comunicação.

A resposta de Gadamer no artigo Réplica à Hermenêutica e Crítica à Ideologia (2004, p. 292 ss.), afirma:

\begin{abstract}
Parece especialmente difícil entender-se sobre os problemas da hermenêutica, pelo menos enquanto conceitos não claros de ciência, de crítica e de reflexão dominarem a discussão. E por isso porque vivemos numa era em que a ciência exerce um domínio cada vez maior sobre a natureza e rege a administração da convivência humana, e esse orgulho de nossa civilização, que corrige incansavelmente as faltas de êxito e produz constantemente novas tarefas de investigação científica, onde se fundamentam novamente o progresso, o planejamento e a remoção de danos, desenvolve o poder de uma verdadeira cegueira. No enrijecimento desse caminho rumo a uma configuração progressiva do mundo pela ciência perpetua-se um sistema no qual a consciência prática do indivíduo se submete resignada e cegamente ou então se rebela revoltosa, e isso significa, não menos cega.
\end{abstract}

Defende que apenas uma absoluta cegueira pode deixar de perceber que a origem histórica e o futuro do ser humano dependem de um saber que não é a ciência, mas está encarregado da direção de toda vida prática humana. Esclarece que até mesmo em Aristóteles, onde se produziu uma fundamental diferença entre o saber produtivo (tekne) e o saber prático (phronesis), em muitos aspectos não restou clara a relação entre o saber político do homem de estado e o saber político do especialista, chegando ao absurdo platônico de colocar como ideal uma ciência de toda ciência: a ciência política. Por força da tradição ocidental de ciência persiste a concepção de que a scientia practica, a filosofia da prática, não é ciência, já que enquanto teoria não seria um saber sobre a ação.

Para Gadamer este tipo de saber não pode ser comparado à gramática ou a retórica que são norteadas por critérios passíveis de produzir uma competência técnica. A filosofia da prática não se caracteriza como saber regulador da práxis humana e social. É uma reflexão sobre a prática, e, portanto, teórica.

Por outro lado, a teoria e o discurso, encontram-se aqui sob condições especiais, à medida que todo saber moral-filosófico e correspondentemente toda teoria geral do estado são relacionadas às condições empíricas especiais do aprendiz (GADAMER, 2004, p. 295). 
Ao considerar a hermenêutica como arte da compreensão e se compreender o exercício dessa arte como um comportamento competente, apenas um saber disciplinar pode fazer uso consciente das regras da arte interpretativa.

Esclarece que a hermenêutica filosófica não está à procura de constituir-se como um meio competente de utilizar as regras.

\begin{abstract}
A hermenêutica filosófica, ao contrário, reflete sobre essa competência e sobre o saber onde essa repousa. Não se presta mais, portanto, à superação de determinadas dificuldades de compreensão como ocorre frente a textos ou no diálogo com outras pessoas, mas o que busca é, como diz Habermas, um "saber reflexivo crítico" (GADAMER, 2004, p. 296).
\end{abstract}

O sentido de crítica da hermenêutica filosófica é o que conduz a uma pretensão de verdade dos discursos. O que critica não é um procedimento científico como tal, mas a falta de justeza metodológica desses procedimentos. Além disso, a hermenêutica filosófica reivindica uma pretensão de universalidade. A universalidade hermenêutica decorre do fato de que nenhuma experiência de mundo pode ser excluída do diálogo e nenhum do campo da ciência moderna escapa desse medium universal de razão prática.

O problema para Gadamer é muito antigo e é o que Aristóteles já tinha em mente quando se referia à ideia geral do bem de Platão. O bem é algo que apenas se pode encontrar na práxis humana e uma ideia geral de "vida justa”, pois enquanto tão somente ideia é vazia. E arremata com séria crítica à Teoria da Ação Comunicativa de Habermas:

\begin{abstract}
Mas para a convivência social das pessoas isso significa que precisamos convencer os outros. E precisamos convencê-los, de certo, não no sentido de que a política e a configuração da vida social sejam uma mera comunidade de diálogo, de modo a sentirnos dependentes de um diálogo livre de coerções, à margem de todas pressões de dominação, como o verdadeiro recurso terapêutico. A política exige a razão que reconduza os interesses para a formação da vontade, e todas as informações sociais e políticas da vontade são dependentes da estrutura das conviç̧ões gerais construídas pela retórica. Isso implica - e creio que isso pertence ao conceito de razão - termos de contar sempre com a possibilidade de que a convicção do outro, seja no âmbito individual ou social, possa estar sempre certa (GADAMER, 2004, p. 320).
\end{abstract}

Na crítica a Habermas, Gadamer chama atenção de que sua pretensão universal de “analista social” que é capaz de evidenciar uma comunicação patológica, o que está a fazer é correndo o risco de perigosamente defender uma pretensão exclusiva de verdade.

A pré-compreensão em Gadamer 
É inconteste no campo jurídico que a “questão” da interpretação da norma exige uma disposição para considerar as diferenças compreensivas, o que constitui uma espécie de “abertura” para o argumento do Outro, que, em não raras vezes é dificultada pelos pré-juízos e pré-compreensões do intérprete. Para uma análise dessa problemática, nos valemos, inicialmente, das lições de Hans-Georg Gadamer sobre hermenêutica, com uma posterior crítica de Habermas sobre a pretensão de universalidade dessa hermenêutica (HABERMAS, 1987).

Gadamer apresenta o problema hermenêutico a partir das experiências estéticas e históricas, assim resumidas:

a) A consciência estética cria uma tradição artística que faz a obra de arte apoderar-se de nós, retirando-nos a liberdade de aceitar ou recusar sua beleza: “quando julgamos algo a partir do ponto de vista de sua qualidade estética, estamos deixando de lado alguma outra coisa que nos atinge muito mais intimamente.” A experiência da arte está, assim, imersa numa soberania estética que aliena a verdadeira percepção da arte (GADAMER, 2004, p. 256-257).

b) A consciência histórica vai se formando lentamente a partir de uma recepção autocrítica “dos testemunhos da vida passada”. Para conhecer o passado é necessário desvincular-se “das realidades atuais que nos prendem à vida presente”. No entanto, ao analisarmos fatos históricos já o fazemos com alguns preconceitos, como as intenções do autor do texto e a situação política da época, o que nos afasta da real interpretação da experiência histórica. E, mesmo que se tente “uma total anulação da individualidade”, haveria o problema “de um espelhamento imediato do presente no passado e do passado no presente”, que leva a um encontro alienado (parcial) da verdadeira experiência: “o encontro com a tradição histórica” (GADAMER, 2004, p. 257).

A consciência que temos na área estética envolve aquilo que, de acordo com nossos gostos, classificamos como belo e agradável aos olhos. Essa consciência pode advir de percepções pessoais ou de influências externas que nos incentivam a aceitar mais determinadas construções visuais. Em uma análise hermenêutica, é possível que a pessoa seja influenciada pelos gostos pessoais, por aquilo que aprendeu a ver como belo ou pelos incentivos constantes dos meios de comunicação. Nossa consciência estética pode ser, portanto, um obstáculo para perceber, compreender e aceitar a consciência estética do outro. Se não há a disposição de entender o ponto de vista do outro, pode-se cometer a injustiça de exigir um padrão que não pode ser suportado pelas pessoas que já habitam aquele local. 
Já a consciência histórica forma-se pelas influências dos nossos antepassados, das nossas experiências de vida, das condições sociais e políticas em que fomos criados. Por um lado, são essas condições que formam nossa individualidade. Por outro lado, elas podem limitar aquilo que poderíamos ser em outras realidades. Na análise hermenêutica, a abertura para o ponto de vista do outro deve permitir-nos entender sua história e as influências que recebeu.

É preciso, para isso, romper a barreira da consciência estética e histórica do 'eu' e considerar as de outrem. Para isso, Gadamer propõe “o desenvolvimento da consciência hermenêutica como uma possibilidade mais abrangente, como contraponto a essa consciência estética e histórica”. A própria tentativa de compreender algo ocorre entre 'um eu e um tu'. A existência do ‘eu’ depende da existência do ‘tu’. Esse é o primeiro consenso estabelecido antes da tentativa de compreender algo. "Mesmo onde tentamos entender-nos a respeito de questões que dividem nossas opiniões, sempre está em jogo esse suporte, mesmo que raramente saibamos” (GADAMER, 2004, p. 261).

Gadamer defende que os preconceitos, em vez de distorcerem a verdade, constituem “a orientação prévia de toda nossa capacidade de experiência” e "se tornam condições para que possamos experimentar qualquer coisa, para que aquilo que nos vem ao encontro possa nos dizer algo. ” Os preconceitos formam o antigo que somos e nos permitem identificar o novo e ter a curiosidade de conhecê-lo (GADAMER, 2004, p. 261).

Em vez de ser um obstáculo, portanto, os preconceitos nos ajudariam a estar dispostos a experimentar o diferente, pois, ao formar nossa identidade, facilitam que aceitemos a identidade do outro. Em outras palavras, o fato de termos conceitos e juízos prévios nos ajuda a perceber que o outro também tem seus conceitos e juízos. Assim, se queremos respeito em relação aos nossos preconceitos, devemos respeitar os do nosso interlocutor.

A ciência moderna, porém, baseia-se "no princípio da imparcialidade e na ausência de preconceitos” o que impediria o condicionamento hermenêutico que pressupõe os preconceitos. No entanto, mesmo os novos conhecimentos e produções da ciência moderna estão baseados em conhecimentos técnicos já existentes, no "nosso comportamento técnico frente ao mundo" (GADAMER, 2004, p. 262).

Mas “a questão hermenêutica não se restringe aos âmbitos de investigação que serviram de ponto de partida”. Busca, também, lançar a base teórica que sustente “o fato fundamental de nossa cultura atual, a ciência e sua utilização técnica industrial”, ou seja, a hermenêutica verifica o objeto de interpretação (fatos) como resposta a algo anterior (perguntas) e tenta descobrir o 
que aconteceriam com os fatos se mudassem as perguntas. "O que constitui verdadeiramente 0 fenômeno hermenêutico originário é que não existe nenhum enunciado que não possa ser compreendido como resposta a uma pergunta, e é só assim que ele pode realmente ser compreendido” (GADAMER, 2004, p. 263).

O historiador não concorda com a influência do presente na investigação do passado. Para ele, as questões relacionadas ao conhecimento histórico "devem ser tratadas independentemente de qualquer relação com a atualidade. ” No entanto, abrir mão da influência de descobertas já realizadas implicaria no constante começar do zero, colocando-se em dúvida “se, com esses procedimentos, a investigação histórica moderna aumenta suas chances de perceber realmente fatos interessantes, adquirindo com isso um correspondente enriquecimento de nosso conhecimento." A tarefa do pesquisador não se resume a conhecer os métodos de sua ciência, devendo incluir uma fantasia, não de imaginar coisas, mas de questionar e de ventilar questões reais e produtivas (GADAMER, 2004, p. 264).

A verdadeira força de atuação da consciência hermenêutica está "no fato de deixar e fazer ver onde está a questão. ” Quando “o todo de nossa vida de experiência” se integra à tradição artística, à tradição histórica dos povos e ao princípio da ciência moderna, é possível formar a "experiência universal e humana de vida”, e, por conseguinte, é possível formar o estrato fundamental que é a “constituição do mundo estruturada na linguagem”. É a linguagem que nos permite ter consciência histórica, pois é a partir da linguagem que "se constrói uma determinada articulação de mundo, um processo que atua como se fosse dirigido e que podemos sempre de novo observar na criança que está aprendendo a falar” (GADAMER, 2004, p. 265266).

A experiência hermenêutica ocorre em um mundo já interpretado, “já ordenado em suas relações, no qual a experiência entra como um elemento novo” que afasta nossas expectativas anteriores para dar lugar a uma nova ordem. Mas são nossas experiências, aquilo que nos é familiar, que possibilita nosso acesso àquilo que é novo, estranho, e isso permite "a ampliação e enriquecimento de nossa própria experiência de mundo” (GADAMER, 2004, p. 268).

A pretensão de universalidade da dimensão hermenêutica está na linguagem utilizada para a compreensão. Apesar da existência de diversas línguas e do constante empobrecimento da linguagem “a construção do próprio mundo continua se dando sempre e simultaneamente na linguagem, sempre que queremos dizer-nos algo uns aos outros” (GADAMER, 2005, p. 612). 
A linguagem é, assim, um meio “em que se reúnem o eu e o mundo”, é aquilo que se pode compreender. É ela que permite a relação humana com o mundo, ao possibilitar a compreensão deste. Por meio da linguagem, a hermenêutica pode adquirir sua dimensão de “questionamento universal”, apresentando-se como “um aspecto universal da filosofia e não somente a base metodológica das chamadas ciências do espírito” (GADAMER, 2005, p. 612613).

O problema hermenêutico relacionado à experiência da arte e da história levou Gadamer a deparar-se "com uma hermenêutica universal que atinge a relação geral do homem com o mundo” (GADAMER, 2005, p. 614). A experiência que se tem com o encantamento daquilo que é belo está relacionada ao conjunto de nossa experiência. Por isso, a hermenêutica não pode ser vista apenas como técnica de compreensão, mas como "uma experiência autêntica, isto é, encontro com algo que se impõe como verdade”. O encontro com o objeto a ser compreendido ocorre "na realização da interpretação dentro da linguagem", o que torna o "fenômeno da linguagem e da compreensão... um modelo universal do ser e do conhecimento” (GADAMER, 2005, p. 625-629).

Gadamer defende, assim, que nenhuma compreensão está "totalmente livre de preconceitos”. Os preconceitos são necessários para complementar os métodos científicos, que, sozinhos, não são suficientes para garantir a verdade. Daí a necessidade “de que o ser próprio daquele que conhece também entre em jogo no ato de conhecer” (GADAMER, 2005, p.631).

Esses preconceitos entram em contato com o objeto em questão por meio da linguagem. “A pretensão de universalidade da hermenêutica filosófica encontra na linguagem o lugar de sua explicitação” (ALMEIDA, 2002, p. 370). Gadamer trabalha a linguagem como um meio para o entendimento entre as pessoas sobre algo que está em questão (ARAÚJO DE OLIVEIRA, 1996, p. 233). A linguagem, porém, “não é um todo pronto e acabado, mas é um contínuo processo de elaboração”, numa relação dialética entre palavra e conceito, e entre conceito e palavra (ALMEIDA, 2002, p. 271-272) No entanto, para que a linguagem assuma seu papel na experiência hermenêutica, não pode ser utilizada “como instrumento de uma consciência manipuladora mas como um meio pelo qual um mundo se coloca face a nós e dentro de nós (PALMER, 1996, p. 243).”

Essas pré-compreensões apontadas por Gadamer, no entanto, não podem servir de “carta branca” para que hermeneuta perceba apenas seu ponto de vista. Por mais que haja uma 
influência da história de cada um, a existência de outros pontos de vista deve ser apreendida pelo intérprete de tal forma que o faça estar disposto a adotar outro ponto de vista.

Ernildo Stein explica que o método crítico-dialético (de Habermas) e o método hermenêutico (de Gadamer) têm em comum a finalidade de "apreender nosso tempo pela reflexão”. Reflexão aqui deve ser entendida como a forma do “ser em si” relacionar-se com o outro, produzindo uma identidade pela oposição. Para se ter a consciência de algo é necessário ter a “consciência de si” e relacionar-se “com conteúdos estranhos a ela. Os dois aspectos da relação consigo e da relação com o outro constituem, de certa forma, a estrutura da reflexão que está na base da consciência” (STEIN, 1987, p.102).

A dupla função da reflexão (unidade e oposição) permite entender como dialética e hermenêutica utilizam-se de métodos divergentes para entenderem o mesmo objeto (nosso tempo). Enquanto a dialética utiliza como método a “diferença e [o] contraste com aquilo sobre o que reflete, a hermenêutica visa primeiramente a mediação e a unificação com o mesmo”. De qualquer forma, a reflexão une os dois métodos e, em ambos, “o ideal da reflexão aparece enquanto busca da racionalidade”. A reflexão realizada pela dialética "acentua a diferença [e] o contraste”, enquanto “a reflexão hermenêutica acentua a identidade”. Nas palavras de Stein: “O método crítico se apresenta basicamente como um instrumento para detectar a ruptura do sentido, enquanto o método hermenêutico busca nos muitos sentidos a unidade perdida” (STEIN, 1987, p. 103).

Pode-se dizer que a hermenêutica tenta entender seu objeto penetrando cautelosamente nele, procurando "tornar-se consciente dos condicionamentos que determinam sua posição dentro da constelação histórica”. A pretensão da universalidade da hermenêutica ocorre justamente porque ela quer compreender "o sentido que nos vem do passado e que abrange, num único movimento, aquele que compreende e aquilo que é compreendido” (STEIN, 1987, p.105).

Stein observa, no entanto, que a pretensão de universalidade é própria tanto do método hermenêutico como do método dialético, por que ambos têm “o desejo de constituir o ponto de partida e o eixo fundamental de posições filosóficas”. Os dois métodos também têm em comum o fato de recusarem a totalidade pretendida pela tradição metafísica, que tinha como ponto de partida o mundo natural ou o mundo teológico. Isso faz com que a totalidade seja buscada "no próprio processo”, no desenvolvimento do "trabalho teórico [...] mas que não se finaliza e não se completa”. Isso concede à dialética e à hermenêutica “uma autoridade epistêmica capaz de 
dar conta de seus pressupostos e produzir níveis de racionalidade cuja legitimação vai-se repondo através do progresso do trabalho teórico” (STEIN, 1987, p. 107-109).

A hermenêutica de Gadamer busca entender as estruturas e as "condições de possibilidade de comunicação” das pessoas entre si. “A comunicação dá-se como compreensão e essa acontece no seio da linguagem”. O sentido universal dessa proposição é o fato de que ela “vale sempre onde se trata da comunicação com os outros”. O horizonte de compreensão está limitado pelas condições históricas e pela finitude do sujeito que compreende, que "não pode escapar da história pela reflexão [pois] dela faz parte”. Isso faz com que “o sujeito [seja] ocupado por preconceitos que pode modificar no processo da experiência, mas que não pode liquidar inteiramente ” (STEIN, 1987, p. 111-112).

A limitação histórica do sujeito pode prejudicar o alcance do objeto que está sendo interpretado. A não ser que haja uma conscientização, o intérprete pode ficar preso aos seus pontos de vista e à sua realidade, sem perceber as condições históricas de outros povos e de outras gerações que não fazem parte de seu horizonte. E os preconceitos advindos das condições em que se encontra o sujeito podem impedi-lo de dar importância a realidades diferentes das suas, como as que encontramos em outras culturas e classes sociais.

Mas Gadamer alerta que os preconceitos podem ser positivos ou negativos. E atribuir um juízo negativo "sobre o preconceito constitui outro preconceito, e um preconceito falso que pode ter drásticas conseqüências, já que sobre ele não se reflete, ficando por isso desapercebido.” Gadamer também defende que o "conhecimento da estrutura do preconceito” permite “uma reabilitação de autoridade e tradição”, que não devem ser vistas, necessariamente, como “fontes de inverdades”, embora reconheça que não possam ser aceitas cegamente (STEIN, 1987, p.112-113).

\section{A crítica de Habermas às pré-compreensões.}

O problema apontado por Habermas à hermenêutica gadameriana é sua tentativa de dissociação entre verdade e método. O “pensamento crítico dialético” trabalhado por Habermas “capta a necessidade da reflexão que a hermenêutica não leva até as últimas consequências”. Ele defende que nem a hermenêutica, nem a dialética, “podem dispensar a questão do método nas ciências para recolocá-la ao nível filosófico para reflexão”. (STEIN, 1987, p.115-116) 
O problema é que Gadamer entende que nossa compreensão é apenas uma descoberta da verdade e, para Habermas, isso impede o reconhecimento da força que a reflexão pode ter sobre a compreensão. É a razão que permite afastar-nos daquilo que aparenta ser absoluto, esclarecendo a gênese da tradição. Habermas também critica a reabilitação que Gadamer promove em relação ao preconceito, pois a estrutura preconceitual deve fazer parte da reflexão que promove a compreensão, e não ter a função de preconceitos (STEIN, 1987, p.115-116).

Ao reabilitar o preconceito, Gadamer acaba por admitir a existência de preconceitos legítimos, notadamente quando a formação da tradição advém dos processos individuais de aprendizagem. Esses preconceitos, no entanto, podem ser legitimados por um educador em função de sua autoridade, que pode provir de sanções ou de promessas de gratificações (HABERMAS, 2012, p.16). O risco, portanto, é que a validade de um preconceito esteja ancorada em uma tradição transmitida por uma autoridade democraticamente ilegítima.

O problema da compreensão hermenêutica é que o sujeito interpreta algo a partir de um contexto previamente dado, condicionado por suas pré-compreensões (do sujeito). No entanto, para alcançar um entendimento universal, a compreensão hermenêutica deve estar inserida em uma estrutura ideal que permita a comunicação ilimitada, livre de coação e de dominação. Ou seja, a pretensão de verdade da tradição exige que ela se tenha formado sem coação e com possibilidade ilimitada de acordo sobre seu conteúdo.

Mesmo que o conhecimento tenha como pano de fundo as tradições fáticas, a reflexão sobre elas tende a modificá-las, não as aceitar como autoridade (STEIN, 1987, p.115-116). Nas palavras de Habermas:

Não há dúvida que o conhecimento se enraíza em tradição [...] fática; ele permanece ligado a condições contingentes. Mas a reflexão não trabalha na faticidade das normas transmitidas [...] sem deixar vestígios. Ela é condenada a chegar depois, mas, ao olhar para trás, desenvolve uma força retroativa. Nós só podemos nos voltar para as normas interiorizadas depois de termos aprendido primeiro cegamente a segui-las sob um poder que se impôs de fora. À medida, porém, que a reflexão recorda aquele caminho da autoridade, no qual as gramáticas dos jogos de linguagem foram exercitadas dogmaticamente como regras da concepção do mundo e do agir, pode ser tirado da autoridade aquilo que nela era pura dominação, e ser dissolvido na coerção sem violência da intelecção e da decisão racional (1987, p. 18). 
Ernildo Stein ensina que Habermas “não recusa a hermenêutica”; até mesmo utiliza, frequentemente, seus instrumentos, reconhece suas realizações positivas e sua "importância ao lado do pensamento crítico”. Apenas entende que a dialética e a crítica das ideologias são superiores a ela, além de criticar sua pretensão de universalidade. Dentre os aspectos positivos da hermenêutica para Habermas, destaca-se sua capacidade de reconstituir a "comunicação perturbada” e de mostrar que as ciências sociais estão estruturadas pela tradição e que o sujeito tem “seu lugar histórico determinado” (STEIN, 1987, p. 122-123).

Habermas defende que a crítica pode pretender ser universal, e é necessário que o seja. (a) A possibilidade dessa pretensão está na capacidade da razão humana, que não deve se limitar a “acolher e reconhecer o que lhe é estranho”, mas também de recusá-lo, superando as forças dogmáticas. A razão não deve apenas confirmar e unir, mas também contestar e dissociar. (b) A pretensão de universalidade da crítica é necessária por que "o contexto da tradição está sistematicamente perturbado" e precisa ser tratado com “interesse emancipatório”. Para isso, "torna-se necessária a crítica das ideologias, que procura tornar transparente o contexto da vida social em todos os seus momentos”. A “comunicação sistematicamente perturbada” ocorre num contexto de alienação, que “nasce da dominação de homens sobre homens”, por isso é necessária uma “comunicação livre de dominação” (STEIN, 1987, p. 125-126).

Sob a ótica da etnometodologia, é necessária a realização de processos cooperativos de interpretação, por meio dos quais os intérpretes interagem mediante "micro-processos da interpretação de situação [...] e de consolidação do consenso [...], que são altamente complexos” mesmo quando o vínculo entre os participantes é uma "habitual compreensão da situação em contextos estáveis de ação”. Essa, no entanto, é uma visão macroscópica, pois, “sob o microscópio, cada entendimento ou acordo [...] se mostra como ocasional e frágil” (HABERMAS, 1987, p. 182).

Já no que se refere à hermenêutica filosófica, o intérprete tem suas certezas que formam um pano de fundo para seus argumentos. Mas, quando em contato com outras realidades, percebem que aquilo que para elas era certeza (já estava pré-estabelecido) para outros se trata de ponto de vista estranho e incompreensível. Nesse momento, “certezas do fundo culturalmente ensaiado se rompem e os meios normais do entendimento falham”. Essa ameaça ao entendimento ocorre mais claramente quando se tenta "penetrar numa língua estrangeira, numa cultura desconhecida ou numa época afastada, e mais ainda nos domínios da vida patologicamente deformados”. Ocorre o que Habermas chama de “comunicação perturbada”, 
já que algumas “condições lingüísticas para um entendimento direto entre (pelo menos) dois participantes da interação não são preenchidas” (HABERMAS, 1987, p. 182-183).

Quem interpreta precisa, assim, diferenciar sua compreensão de um fato da interpretação realizada por outrem, entendendo a realidade contextual (mundo da vida) desse. Precisa entender, em relação ao objeto de interpretação ou às pessoas afetadas, suas crenças, valores, vivências, intenções e sentimentos, para descobrir o que pode estar querendo dizer em cada argumento. Assim, poderá verificar por que o outro considera algumas informações como verdadeiras, ou entende alguns valores como corretos, ou, ainda, manifesta suas vivências como verazes (HABERMAS, 2012, p. 183-184).

Para que se desenvolva um processo de compreensão, o indivíduo "teria de se desvencilhar do horizonte de seu tempo, de maneira semelhante a como nós ampliamos nosso próprio horizonte, enquanto intérpretes, ao nos envolvermos com o texto dele” (HABERMAS, 2012, p. 249-250). Precisa-se, até mesmo, reconstruir os processos de aprendizagem dos demais destinatários da norma, o que poderia explicar o fundamento dos aspectos essenciais de um modo de vida. A compreensão do mundo não está mais centrada, assim, no que está interpretando, mas também nos demais destinatários da interpretação.

\section{Considerações Finais.}

O formalismo legal, a bem-sucedida solução metodológica do positivismo jurídico do século XIX, encontrou na hermenêutica jurídica um instrumental eficiente de operacionalidade da “ciência do direito”, permitindo a redução da atividade compreensiva num ato restrito de reprodução de seu "objeto científico privilegiado": o texto legal. Assim, o trabalho do jurista é convertido numa exegese reduzida capaz de especificar e concretizar o texto legal, limitada subsunção de aplicação da norma geral e abstrata ao caso concreto. Um simples trabalho silogístico no qual a premissa maior é o sistema normativo e a premissa menor o fato concreto, sendo a conclusão necessária a decisão. Tal autêntica fé epistemológica trouxe em si a negação do inegável: a questão da pré-compreensão ou pré-conceito, para tomar por empréstimo a linguagem gadameriana.

O postulado hermenêutico nuclear construído sobre esta crença epistemológica, é o de reproduzir os ideais de plenitude, coerência, universalidade e a-temporalidade do sistema 
normativo, o que permitem, enquanto instância racional, a elaboração de ficções hermenêuticas, como a "vontade do legislador” e “vontade da lei”, de múltiplas funções práticas e ideológicas. Inicialmente, esses postulados justificam a atividade compreensiva do direito como ato formal, excluindo qualquer possibilidade de criação por parte do intérprete e inferência de elementos substanciais, em nome da igualmente ficção “segurança jurídica”.

Com a emergência das correntes críticas do Direito e, por via de consequência, a revisão dos postulados tradicionais da hermenêutica jurídica e concepções emprestadas da filosofia, ganham relevância pensadores como Gadamer e Habermas, dois grandes herdeiros do pensamento moderno que colocam em questão dois grandes discursos sustentadores das práticas jurídicas e legitimadores da discricionariedade judicial: a ideologia como elemento indissociável da compreensão e a problematização da verdade. Desde matrizes teóricas distintas ambos pensadores anunciam o fim da natureza epistemológica da hermenêutica e com ela igualmente o fim da razão moderna. Enfim, tempos de crise. Tempos em que a filosofia perde o fundamento que vincula o significante ao significado ontologicamente e passa a buscar a universalidade e o sentido pela linguagem. Tempos em que o pensamento jurídico também busca se reinventar mesmo correndo o risco de se perder no infindável relativismo ou mesmo a redução ideológica. Risco necessário correr porque é tarefa urgente.

\section{REFERÊNCIAS.}

ALMEIDA, Custódio Luís Silva de. Hermenêutica e dialética: dos estudos platônicos ao encontro com Hegel. Porto Alegre: EDIPUCRS, 2002.

GADAMER, Hans-Georg. A universalidade do problema hermenêutico. In: Verdade e Método II: complementos e índice. 2. ed. Tradução de Enio Paulo Giachini. Petrópolis, RJ: Vozes; Bragança Paulista, SP: Editora Universitário São Francisco, 2004.

GADAMER, Hans-Georg. Verdade e Método I: Traços fundamentais de uma hermenêutica filosófica. 7. ed. Tradução de Flávio Paulo Meurer. Petrópolis, RJ: Vozes; Bragança Paulista, SP: Editora Universitário São Francisco, 2005.

HABERMAS, Jürgen. Ciência y Técnica como Ideología. Tradução de Manuel Jiménez Redondo. Madrid: Tcnos, 1986.

HABERMAS, Jürgen. Dialética e Hermenêutica - para a crítica hermenéutica de Gadamer. Ed: LP\&M, 1987. 
HABERMAS, Jürgen. Teoria de la Accion Comunicativa, tomo I, Racionalidad de la acción y racionalización social, tomo II, Crítica de la razón funcionalista, versión castellana de Manuel Jiménez Redondo. Madrid: Taurus Ediciones, 1987.

HABERMAS, Jürgen. Teoria do Agir Comunicativo, vol. 1: racionalidade da ação e racionalização social. Trad. Paulo Astor Soethe; vol. 2: sobre a crítica da razão funcionalista. Trad. Flávio Beno Siebeneichler. São Paulo: Editora WMF Martins Fontes, 2012.

OLIVEIRA, Manfredo Araújo de. Reviravolta Lingüístico-Pragmática. São Paulo: Ed. Loyola, 1996.

PALMER, Richard E. Hermenêutica. Tradução de Maria Luísa Ribeiro Ferreira. Lisboa: Edições 70, 1996.

STRECK, Lenio Luiz. Verdade e Consenso - constituição, hermenêutica e teorias discursivas. $5^{\text {a }}$ ed., São Paulo: Saraiva, 2014.

STEIN, Ernildo. Dialética e Hermenêutica: Uma Controvérsia sobre Método em Filosofia. In: HABERMAS, Jürgen. Dialética e Hermenêutica: para a crítica da hermenêutica de Gadamer. Trad. Álvaro L. M. Valls. Porto Alegre: L\&PM, 1987. 